\title{
LEGITIMIDAD DEL SISTEMA CHILENO DE JUSTICIA PENAL NEGOCIADA A LA LUZ DE LA JURISPRUDENCIA INTERNACIONAL DE DERECHOS HUMANOS
}

\author{
LEGITIMACY OF THE CHILEAN NEGOTIATED CRIMINAL \\ JUSTICE SYSTEM IN THE LIGHT OF INTERNATIONAL HUMAN \\ RIGHTS JURISPRUDENCE
}

\author{
Guillermo Oliver Calderón* \\ TOMÁs Correa URMeneta ${ }^{* *}$
}

RESUMEN: En este trabajo, se revisa jurisprudencia del Tribunal Europeo de Derechos Humanos sobre justicia penal negociada, se extrae de ella criterios de legitimidad de dicha forma de juzgamiento de delitos y se analiza el grado de cumplimiento de tales criterios en el sistema procesal penal chileno.

Palabras clave: Justicia penal negociada, procedimiento abreviado, procedimiento simplificado con admisión de responsabilidad, procedimiento monitorio, renuncia al juicio oral.

ABSTRACT: This paper reviews the jurisprudence of the European Court of Human Rights on negotiated criminal justice, extracts criteria of legitimacy of such form of trial of crimes and analyzes the degree to which such criteria are met in the Chilean criminal procedure system.

Keywords: Negotiated criminal justice, abbreviated procedure, simplified procedure with admission of liability, order for payment procedure, waiver of oral proceedings.

\section{INTRODUCCIÓN}

La expresión "justicia penal negociada” se usa en referencia a acuerdos por los cuales el imputado renuncia al juicio, a cambio de un beneficio penal o procesal, bajo control judicial $^{1}$, y puede ser entendida en un sentido restringido o en uno amplio. En sentido restringido, es usada para aludir a mecanismos de negociación que conducen a una absolución

\footnotetext{
Doctor en Derecho por la Universidad de Barcelona. Profesor de Derecho Penal y Derecho Procesal Penal de la Pontificia Universidad Católica de Valparaíso. Dirección electrónica: guillermo.oliver@pucv.cl. Dirección postal: Avenida Brasil 2950, Valparaíso, Chile. ORCID: https://orcid.org/0000-0003-4485-1870.

** Licenciado en Ciencias Jurídicas por la Pontificia Universidad Católica de Valparaíso. Dirección electrónica: tomascorreaurmeneta@gmail.com. Dirección Postal: Medio Oriente 1050, Oficina 301, Viña del Mar, Chile. Este trabajo es un producto del proyecto de investigación Fondecyt Regular No 1170949, ejecutado por el Departamento de Derecho Penal y Derecho Procesal Penal de la Pontificia Universidad Católica de Valparaíso en el período marzo 2017 - marzo 2020.

Los autores agradecen a la Fiscal Regional de Valparaíso del Ministerio Público, Claudia Perivancich Hoyuelos, por su ayuda en la obtención de información estadística usada en este trabajo. Agradecen también a Agustina Alvarado Urízar, Guillermo Améstica Zavala, Ignacio Barrientos Pardo, Julián López Masle, Daniel Polanco Valdés y Paola Rojas Caro por la facilitación de jurisprudencia pertinente.

1 Correa y Reyes (2012) pp. 17-18.
} 
o a una condena en un proceso penal. En sentido amplio, se la utiliza para hacer referencia a cualquier acuerdo que el imputado puede celebrar en un proceso penal, aun cuando no conduzca a una sentencia condenatoria o absolutoria ${ }^{2}$. En lo sucesivo, tal expresión será usada en sentido restringido.

En las últimas décadas, los mecanismos de justicia penal negociada, de antigua raigambre en el sistema jurídico anglosajón, han ido proliferando en los países adscritos al sistema europeo continental ${ }^{3}$, tras una recomendación del Consejo de Ministros del Consejo de Europa, de $1987^{4}$. Con ello, las críticas que desde antiguo se han formulado, especialmente contra el plea bargaining norteamericano ${ }^{5}$, se han extendido a la Absprache alemana, al Patteggiamento italiano, a la "conformidad" española, etc.

El objetivo de este trabajo es revisar la jurisprudencia internacional de derechos humanos en el ámbito de la justicia penal negociada, para extraer de ella criterios de legitimidad de su funcionamiento y evaluar su grado de cumplimiento en el modelo chileno. Ante la ausencia de pronunciamientos relevantes en esta materia a nivel interamericano, nos concentraremos en fallos dictados por el Tribunal Europeo de Derechos Humanos (en adelante, TEDH), en casos en que acuerdos en el proceso penal han generado, según los solicitantes, menoscabos de derechos fundamentales que infringen normas establecidas en el Convenio Europeo (o Convención Europea) de Derechos Humanos (en lo sucesivo, $\mathrm{CEDH}$ ). Ello no es un problema para el objetivo de este trabajo, pues es sabido que la Corte Interamericana de Derechos Humanos utiliza frecuentemente la jurisprudencia de su par europeo para (comenzar a) definir sus estándares ${ }^{6}$.

\section{JURISPRUDENCIA DEL TEDH SOBRE JUSTICIA PENAL NEGOCIADA}

En los últimos años, el TEDH ha realizado importantes pronunciamientos acerca de posibles afectaciones a derechos consagrados en la $\mathrm{CEDH}$ con motivo de la aplicación de sistemas de justicia penal negociada, especialmente respecto de países de Europa del este. A continuación, se ofrece una sistematización de tales pronunciamientos.

\section{JUSTICIA PENAL NEGOCIADA Y DERECHO A SER OÍDO EQUITATIVA Y PÚBLICAMENTE}

Uno de los puntos sobre los que se ha pronunciado el TEDH es el derecho al debido proceso penal, consagrado en el artículo 6 de la CEDH como "derecho al proceso equitativo". Esta disposición indica que "[t]oda persona tiene derecho a que su causa sea oída equitativa, públicamente y dentro de un plazo razonable, por un tribunal independiente e imparcial, establecido por ley, que decidirá los litigios sobre sus derechos y obligaciones de carácter civil o sobre el fundamento de cualquier acusación en materia penal dirigida con-

\footnotetext{
2 Véase Herrera (2014) pp. 57-69; Oliver (2019a) p. 451.

3 LANger (2001) p. 97.

4 Del Corral (2010) p. 50.

5 Por todos, Langbein (1978) pp. 3-22.

6 Dias (2015) p. 200.
} 
tra ella" (art. 6.1). El artículo 8.1 de la Convención Americana sobre Derechos Humanos (en adelante, $\mathrm{CADH}$ ) señala esta idea en forma muy similar.

Al ser la justicia penal negociada una figura de reciente incorporación en los países europeos no existía un tratamiento jurisprudencial sistemático respecto del tema en materia de derechos humanos hasta el año 2014, cuando el TEDH dictó su fallo en el caso llamado Natsvlishvili y Togondize v. Georgia ${ }^{7}$. Hacía falta una sentencia en la que se analizase detalladamente la regulación sobre estos acuerdos, haciendo especial énfasis en el problema de la validez del consentimiento del acusado al momento de celebrar el pacto ${ }^{8}$. Es un fallo considerado de gran importancia, pues ha sentado jurisprudencia en cuanto a la legitimidad de los acuerdos en el proceso penal en los diferentes países de Europa.

El primer solicitante, Amiran Natsvlishvili, fue vicealcalde de la segunda ciudad más grande de Georgia, Kutaisi, y director general de la Planta Automotriz de la misma ciudad entre 1995 y 2000, una de las empresas más grandes del país ${ }^{9}$. En diciembre de 2002, fue secuestrado, sufriendo malos tratos por parte de sus secuestradores y siendo liberado a cambio de una gran suma de dinero, pagada por su familia ${ }^{10}$.

En marzo de 2004, Natsvlishvili fue acusado de reducir ilegalmente el capital social de la fábrica, como director general de ella y como presidente del comité de supervisión, siendo detenido días después. Posteriormente, el fiscal solicitó la prisión preventiva en su contra, siendo esta solicitud acogida por el tribunal.

Mientras se encontraba en prisión preventiva, el solicitante manifestó su deseo de llegar a un acuerdo con la justicia, mediante la transferencia de las acciones de la fábrica que se encontraban en posesión suya y de su cónyuge, siendo transferido el $15.55 \%$ de las acciones al Estado, en septiembre de $2004^{11}$. Días después, el solicitante envió una declaración por escrito al fiscal, pidiendo que se llegara a un acuerdo sobre el procedimiento, indicando que, aun cuando se consideraba inocente, tenía intención de llegar a un acuerdo sobre la sentencia y reparar el daño causado al Estado, ofreciendo pagar una suma de dinero al Fisco y añadiendo que comprendía a cabalidad el contenido de tal acuerdo. El fiscal de Kutaisi le ofreció llegar a una sentencia en virtud de un plea bargain, considerando su disposición a reparar el daño causado mediante el pago de dinero y la transferencia de acciones al Fisco, lo que el imputado aceptó. En virtud de lo anterior, el fiscal indicó que, sin perjuicio de que se arriesgaba una pena que iba desde los seis a los doce años de presidio, el acuerdo era posible, por razones de eficiencia respecto de los recursos estatales y porque el solicitante estaba dispuesto a reparar los perjuicios causados, siendo aprobado el acuerdo en audiencia oral el día siguiente por la Corte de la ciudad de Kutaisi. Natsvlishvili manifestó su conformidad nuevamente en el asunto, indicando junto con su abogado, que no fue sujeto de presiones o coerción. En consecuencia, el tribunal declaró al solicitante como cul-

\footnotetext{
DiAS (2015) pp. 225-226.

8 DiAs (2015) p. 227.

9 Caso Natsvlishvili y Togondize V. GeORgia (2014), párrafo 9.

10 Caso Natsvilshvili y Togondize V. GeORgia (2014), párrafo 11.

11 Caso NatsvilshVili y Togondize V. Georgia (2014), párrafos 12-16 y 21.
} 
pable y, en virtud del plea agreement, lo condenó a pagar la suma de dinero ya mencionada, siendo liberado inmediatamente ${ }^{12}$.

A juicio de los solicitantes ante la Corte de Estrasburgo, el uso del plea bargaining fue contrario a lo dispuesto en el artículo 6.1 de la $\mathrm{CEDH}$, ya que no estuvo acompañado de resguardos ante abusos de la autoridad. Circunstancias como que el modelo de Georgia no permitiera que el juez revisara suficientemente la conveniencia del plea agreement y que el sistema no ofreciera un funcionamiento justo -teniendo una tasa de condena del 99\%-, habrían hecho que la decisión del imputado no fuera completamente voluntaria y constituyera la vía que tenía para escapar del encarcelamiento. Argumentaron también que el sistema de justicia penal negociada de Georgia contempla derechos y privilegios sin restricciones para la autoridad persecutora, no existiendo iguales condiciones de negociación entre los intervinientes ${ }^{13}$.

El TEDH considera que es un elemento común de los sistemas procesales penales europeos que el acusado obtenga una reducción de cargos o una reducción de sentencia a cambio de una declaración de culpabilidad o de nolo contendere, o al proveer una sustancial cooperación con la autoridad que investiga. Indica, asimismo, que al ser el efecto de este mecanismo que los cargos criminales en contra de un acusado se determinen por una forma abreviada de revisión judicial, habría una reducción del número de derechos procesales para el imputado, lo que no es en sí mismo un problema, porque ni la Carta de Derechos Humanos ni el espíritu del artículo 6 de la CEDH evitan que una persona pueda ver reducidos sus resguardos procesales por voluntad propia. De todos modos, la Corte señala que es un principio fundamental que cualquier renuncia de algún derecho procesal debe siempre ser establecida en términos inequívocos, contar con un mínimo de garantías y no ser contraria a ningún interés público ${ }^{14}$.

En el caso particular, el fallo menciona que, al acordar una negociación con la autoridad persecutora sobre la sentencia y declarar no contest en relación con los cargos formulados en su contra, el solicitante renunció a su derecho a que el caso penal se examinara en su mérito. La Corte argumenta que la aceptación de este acuerdo debió haber contado con las siguientes condiciones: (1) la oferta debe haber sido acordada con pleno conocimiento del solicitante de los hechos del caso y las consecuencias legales, de forma genuinamente voluntaria, y (2) el contenido de la oferta y la justicia respecto de la forma en que las negociaciones fueron alcanzadas entre los intervinientes debe ser sujeta a revisión judicial suficiente. Considerando esto, el TEDH argumenta que fue el mismo solicitante quien pidió al fiscal la negociación de un acuerdo y expresó su deseo de reparar el daño, teniendo acceso al expediente y siendo representado por abogados de su elección. Además, afirma que, en varias ocasiones, el solicitante señaló que entendía el contenido del acuerdo, sus derechos dentro del proceso y las consecuencias derivadas del plea bargain. Se hace énfasis también en que Natsvlishvili indicó que su decisión de aceptar no fue resultado de coacción o falsas promesas, y que existió un acuerdo por escrito que fue firmado por el solicitante y su abo-

\footnotetext{
12 Caso Natsvlishvili y Togondize V. GeORgia (2014), párrafos 25 a 31.

13 Caso Natsvishrilli Y Togondize V. GEORGIA (2014), párrafos 81 a 84.

14 Caso Natsvlishvili y Togondize V. Georgia (2014), párrafos 87 y 88.
} 
gado, además de destacar que el Tribunal de Kutaisi, basándose en la legislación interna de Georgia, tampoco estaba obligado a aceptar el acuerdo, teniendo el poder de rechazarlo o reducirlo al momento de acordar la revisión ${ }^{15}$. Considerando todos estos factores, la Corte concluye que no ha existido violación del artículo 6.1 de la Convención.

En definitiva, lo que hace el TEDH es establecer que, bajo los parámetros del artículo mencionado, la práctica de obtener una sentencia más favorable por la vía del plea bargaining no representa un problema en cuanto al derecho a un proceso equitativo, siempre que el imputado haya accedido voluntariamente al pacto, entendiendo su contenido y consecuencias. Si así es el caso, el acuerdo no puede ser discutido ante el TEDH ${ }^{16}$.

Analizando este fallo, Dias indica que la justificación que hace la Corte Europea de los acuerdos en el proceso penal es problemática, porque cuando señala que la adopción de mecanismos consensuales es una característica común a los sistemas europeos, parece esgrimir un argumento de autoridad ${ }^{17}$. Es decir, le otorga legitimidad a este sistema solo por presentar una aplicación cada vez más extendida en los distintos ordenamientos jurídicos, sin hacer énfasis en los riesgos que conlleva.

Por su parte, Bachmaier destaca que el TEDH centra su análisis en el cumplimiento formal de las garantías que regulan la conformidad, sin entrar a considerar otros elementos que son ajenos al cauce procesal y que pueden conducir a la conclusión de que la renuncia al juicio y la sentencia consensuada fueron, en este caso particular, el resultado de un acuerdo obtenido bajo coerción ${ }^{18}$.

En esta causa, efectivamente, hay dos puntos que sugieren que la voluntad del acusado pudo haber sido constreñida para aceptar un acuerdo de conformidad. En primer lugar, un dato relevante son las paupérrimas condiciones de la prisión preventiva del solicitante, llegando al punto de tener que compartir durante los primeros cuatros meses la misma celda con la persona que lo secuestró el año 2002, además de encontrarse también con otra persona que cumplía una condena por homicidio, lo que implicaba, a juicio del defensor, un riesgo para su bienestar físico y psicológico ${ }^{19}$.

En segundo lugar, otro elemento crucial es la alta tasa de condena que tiene el sistema de justicia penal de Georgia, siendo el porcentaje de acusados absueltos prácticamente cero $^{20}$. Así, prevalece la idea del riesgo de llegar a juicio, lo que se traduce en la posibilidad de sufrir la imposición de una pena más gravosa o ser castigado por un delito más grave ${ }^{21}$, por lo que, ante la seguridad de ser condenado, la mejor oportunidad del imputado es buscar la opción de obtener la pena menos perjudicial, lo que también puede constituir una forma de coerción ${ }^{22}$.

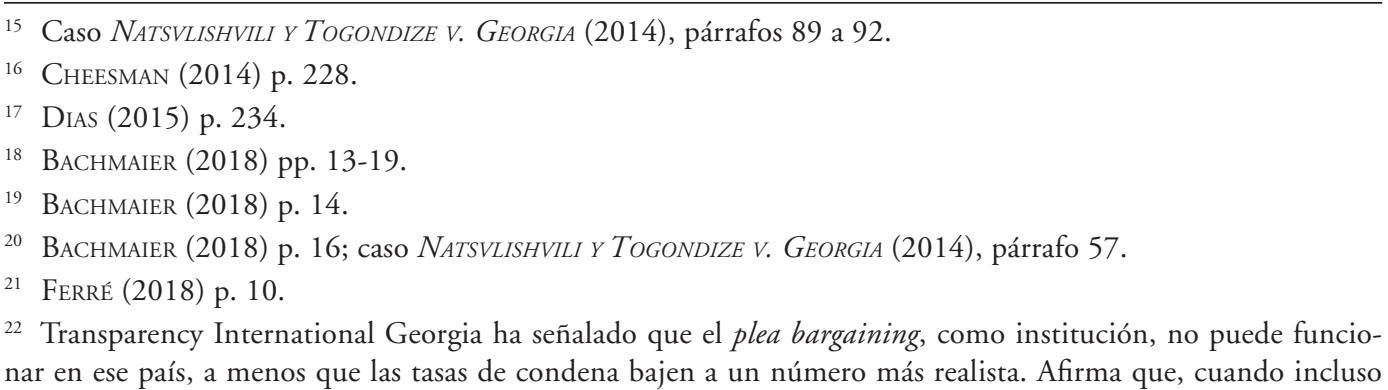


Si bien el fallo no advierte la influencia de estos elementos como eventuales presiones, hay un voto parcialmente disidente de la jueza Alvina Gyulumyan, que hace énfasis en las críticas señaladas, indicando que el Tribunal de Kutaisi no pudo haber examinado debidamente si existió una posición de igualdad entre los intervinientes, al no existir un completo registro de las negociaciones. Además, factores como la falta de transparencia en gran parte de las circunstancias de hecho vinculadas con el caso, la ya señalada tasa de condena que se presenta en el país y la actitud que tuvo la autoridad fiscal en el manejo del caso, dan cuenta de la posición de ventaja que tuvo esta en las negociaciones (párrafos 3 y 4).

Posteriormente, el TEDH confirmó los criterios para examinar la legitimidad de los acuerdos de plea bargaining, en el caso Kadagishvili v. Georgia, del año 2020. En dicha decisión, la Corte reitera que si el acuerdo de conformidad se lleva a cabo con asistencia letrada, es acompañado de una adecuada revisión judicial y la manifestación de quienes acceden al acuerdo es realizada en ausencia de cualquier presión, no existe infracción del artículo 6.1 de la $\mathrm{CEDH}^{23}$.

\section{Justicia penal Negociada, RenUnCia AL DERECHO A SER oído y CALidAd DE VÍCTIMA \\ Uno de los puntos contemplados en el artículo 6.1 de la CEDH y que ha sido objeto} de análisis por el TEDH, es el derecho a ser oído. Este aspecto es desarrollado en el fallo del caso Leuska y otros v. Estonia, que data de noviembre de 2017.

El hijo de dos de los solicitantes (ambos de apellido Leuska) murió en un accidente de tránsito. Estos, junto con los demás demandantes, interpusieron una acción civil en el procedimiento penal en contra del supuesto autor del delito, buscando la compensación del daño extrapatrimonial y el reembolso de las costas legales ${ }^{24}$. Posteriormente, llegaron a un acuerdo extrajudicial con el supuesto autor, informando al fiscal que habían acordado que el caso sería resuelto mediante tal arreglo. Así, J., como nombra el fallo al imputado, informó que había pagado la compensación a los solicitantes. Del mismo modo, el consentimiento de las víctimas fue registrado en un reporte firmado por estas y sus abogados, el que indicaba que fueron informados de los derechos y consecuencias derivados del acuerdo, además de manifestar su renuncia a las reclamaciones vinculadas con el daño extrapatrimonial, pero que no renunciarían a aquellas relacionadas con las costas legales. Así, en febrero de 2011, J. manifestó su consentimiento definitivo en el procedimiento de acuerdo, indicándose en este que las víctimas retiraban también las acciones civiles derivadas del procedimiento penal. En virtud de lo anterior, se citó a J., a su abogado y al fiscal a audiencia, sin ser convocadas las víctimas. Antes de la fecha de la audiencia, las víctimas presentaron una reclamación a la Corte del Condado de Harju por las costas legales. El día de la audiencia, el imputado pidió que no se examinara la demanda de las víctimas por el reembolso de las costas legales, al encontrarse estas últimas absorbidas por el acuerdo extrajudicial.

los imputados inocentes sienten la necesidad de "admitir culpabilidad" debido a las bajas tasas de absolución, el poder queda concentrado en manos de los fiscales. Véase Transparency (2010) p. 14.

23 Caso Kadagishvili V. GEORGia (2020), párrafos 156 y 160.

24 Caso LEUSKA Y OTROS V. ESTONIA (2017), párrafos 6 y 8. 
Los solicitantes alegaron que no les fue permitido dirigirse a la Corte, a pesar de encontrarse físicamente en ese lugar. Por su parte, el fallo del tribunal no hizo referencia alguna a las costas legales en las que se incurrió en el procedimiento ${ }^{25}$.

Ante ello, los demandantes interpusieron un recurso, alegando que no se les permitió participar de la audiencia y que el tribunal no resolvió su reclamación vinculada con el reembolso de las costas. La Corte del Condado de Harju se negó a hacer un examen de dicho recurso, puesto que consideró que los solicitantes no tenían la calidad de partes y, por consiguiente, no tenían derecho a recurrir. Los solicitantes apelaron a esta decisión, insistiendo en que habían sido intervinientes en el procedimiento y podían recurrir ante las decisiones del tribunal. Sin embargo, la Corte de Apelaciones rechazó este recurso, reafirmando que las víctimas, al suscribir un acuerdo con el imputado, no eran consideradas como partes y, por lo mismo, no tenían los derechos propios de esta calidad. Además, esta Corte señaló que tal decisión era inapelable. Los afectados intentaron llevar el caso ante la Corte Suprema, pero esta se negó a revisar o resolver el caso $^{26}$.

El gobierno de Estonia, al momento de hacer las presentaciones vinculadas con la demanda ante el TEDH, argumentó que los solicitantes no podían ser considerados como víctimas, en los términos del artículo 34 de la $\mathrm{CEDH}$, puesto que todas sus reclamaciones existentes o potenciales, incluyendo su reclamación por las costas legales, fueron cubiertas por el acuerdo extrajudicial ${ }^{27}$.

La Corte Europea enfatiza que una decisión o medida favorable para el demandante no es, en principio, suficiente para privarlo de esta calidad, a menos que las autoridades nacionales hayan reconocido expresa o tácitamente una infracción a la Convención, y luego hayan logrado su adecuada reparación ${ }^{28}$. Este tribunal ya había hecho un pronunciamiento similar, en el caso Dimitrov y Hamanov v. Bulgaria el año $2011^{29}$. Por lo mismo, la circunstancia de si las demandas de los solicitantes fueron cubiertas por un acuerdo extrajudicial resulta irrelevante para la determinación de su calidad de víctimas, en relación con sus anteriores reclamaciones, agregando la Corte que el Estado demandado no ha reconocido una violación al artículo 6.1 de la Convención ni ha ofrecido reparación alguna, por lo que los demandantes deben ser considerados como víctimas ${ }^{30}$.

En cuanto a la afectación del derecho a ser oído, el criterio del tribunal en este fallo busca determinar si, ante este acuerdo, los solicitantes renunciaron válidamente a su derecho de participar en la audiencia del tribunal. La Corte Europea toma en cuenta las

\footnotetext{
25 Caso LEUSKA Y OTROS V. ESTONIA (2017), párrafos 9-15.

26 Caso LEUSKA Y OtROS V. ESTONIA (2017), párrafos 16-22.

27 Caso LEUSKA Y OTROS V. ESTONIA (2017), párrafo 44.

28 Caso LEUSKA Y OTROS V. ESTONIA (2017), párrafo 56.

29 Confrontar con Dimitrov y Hamanov v. Bulgaria (2011), párrafos 59 y 60. En este caso, la Corte también hace énfasis en que los casos en que se puede privar a un demandante de su calidad de víctima se vinculan con aquellas situaciones en que las autoridades nacionales hayan reconocido un incumplimiento a lo establecido en la Convención y luego hayan hecho algún tipo de reparación, pero lo vinculan al hecho de que el plea bargaining no puede ser considerado como una forma de haber otorgado una reparación expresa en relación con la infracción a la garantía del plazo razonable.

30 Caso LeUsKa y otros v. ESTONIA (2017), párrafos 58 y 59.
} 
normas del derecho interno de Estonia, argumentando que se estaba frente a una excepción al procedimiento penal ordinario y que los solicitantes, representados por abogados de su elección, fueron informados de los derechos y consecuencias del acuerdo antes de consentir en su aplicación, no siendo posteriormente citados a presentarse en audiencia. Indica, además, que ante dichas circunstancias, el consentimiento de los solicitantes en el acuerdo se considera como una renuncia inequívoca de sus derechos sobre el procedimiento, incluyendo el derecho a ser oído, concluyendo que el hecho de que los demandantes no fueran escuchados por la Corte del Condado de Harju no constituye una contravención al artículo 6.1 de la $\mathrm{CEDH}^{31}$.

\section{Justicia penal negociada y derecho a ser oído dentro de un plazo RAZONABLE}

En el caso Dimitrov y Hamanov v. Bulgaria, la Corte analiza el criterio del plazo razonable en relación con el cuestionamiento que hacen los intervinientes sobre si el plea bargaining se considera como una solución frente a una efectiva dilación indebida.

En septiembre de 1995, tras ser detenido por la policía al intentar ingresar a un automóvil ajeno junto con dos individuos, el señor Dimitrov hizo una confesión escrita. Sin embargo, recién en marzo de 2002 fueron formulados cargos en su contra, siendo entrevistado en presencia de su abogado y declarándose culpable. Respecto de los otros dos sujetos, el ente investigador no formuló cargos. En mayo del mismo año, considerando que uno de estos sujetos se encontraba fuera de Bulgaria y que era imposible establecer los hechos sin contar con su declaración, sumado a la necesidad de acusar también a este, la oficina del Fiscal de Distrito de Plovdiv decidió mantener en espera el procedimiento hasta su regreso, reanudándose en el año 2005. Sin perjuicio de lo anterior, este sujeto fue interrogado como testigo, no siendo ni este ni el otro individuo involucrado finalmente acusados. Recién en julio de 2005, Dimitrov pudo tener conocimiento del expediente y fue formalmente acusado (indicted) en agosto de ese año. La audiencia de juicio se realizó el 18 de mayo de 2006, en la cual el imputado y el fiscal señalaron que habían acordado un plea bargain. La Corte de Distrito de Plovdiv revisó y aprobó el acuerdo, condenando al acusado ${ }^{32}$.

La discusión ante el TEDH se enfoca en determinar si el hecho de que el solicitante haya aceptado un acuerdo significó una solución a la excesiva dilatación que estaba teniendo la causa. El gobierno de Bulgaria afirmó que, al resolver el asunto por esta vía, Dimitrov se estaba beneficiando con un tratamiento más favorable, agregando que la finalidad de los acuerdos es prevenir procedimientos largos ${ }^{33}$. Por su parte, Dimitrov sostuvo que la duración del procedimiento seguido en su contra no jugó ningún rol en la conclusión del caso por la vía de la justicia penal negociada, ni fue considerada como factor para que la Corte de Distrito de Plovdiv aprobara el acuerdo ${ }^{34}$.

\footnotetext{
31 Caso LeUSKA Y OtROS V. ESTONIA (2017), párrafos 75-77.

32 Caso Dimitrov y Hamanov V. Bulgaria (2011), párrafos 7-15.

33 Caso Dimitrov y Hamanov v. Bulgaria (2011), párrafo 57.

34 Caso Dimitrov y Hamanov v. Bulgaria (2011), párrafo 58.
} 
La Corte de Estrasburgo indica que los acuerdos no pueden ser considerados como un reconocimiento del fracaso de las autoridades para determinar los cargos penales dentro de un plazo razonable, o como una forma de haber otorgado una reparación expresa y mensurable al demandante en relación con este hecho ${ }^{35}$. Por consiguiente, la Corte entiende que la demanda de Dimitrov debe ser admitida, afirmando que ha existido una infracción a lo dispuesto en el artículo 6.1 de la $\mathrm{CEDH}^{36}$.

\section{JUSTICIA PENAL NEGOCIADA ANTE COACUSADOS Y PRESUNCIÓN DE INOCENCIA}

Uno de los puntos más discutidos respecto de la implementación del plea bargaining se vincula, en casos en que existen coimputados, con la posible afectación al derecho de presunción de inocencia, garantía que ha sido considerada como un principio político sobre el cual está estructurado todo el proceso penal moderno y que goza de consagración expresa tanto en la CEDH como en la $\mathrm{CADH}^{37-38}$.

En el caso Navalnyy y Ofitserov v. Rusia se aborda el problema del uso de antecedentes y de una sentencia dictada en el marco del plea bargaining en otras causas relacionadas en que los imputados no se acogieron a este tipo de acuerdos. Se trata de un caso en que los solicitantes alegaron una vulneración a la presunción de inocencia, al resolverse la causa de un imputado por la vía de la justicia penal negociada y utilizarse tales antecedentes en el juzgamiento ordinario de los dos solicitantes.

Los solicitantes sostuvieron que el proceso seguido en su contra fue arbitrario e injusto, alegando una vulneración a la presunción de inocencia, basada en cómo se utilizaron los hallazgos establecidos en el juzgamiento en contra de otro imputado -a quien el fallo se refiere como "X" y que fue condenado en virtud de un plea bargain- respecto de la participación de los demandantes en el crimen por el que se les persiguió, el uso de la evidencia originada en ese otro procedimiento y el juzgamiento mismo, en el juicio en su contra ${ }^{39}$. Los demandantes señalaron ante el TEDH que ellos no habían sido partes en el procedimiento seguido en contra de "X", por lo que no pudieron reclamar sobre la decisión o evidencia relativa al caso, a pesar de lo cual el juzgamiento de este imputado formó la base de la condena en contra de ellos ${ }^{40}$. Agregaron que el juzgamiento anterior, por aplicación del artículo 90 del Código Procesal Penal de Rusia, era considerado como cosa juzgada ${ }^{41}$.

El TEDH determina que, incluso cuando la ley señala que ninguna inferencia sobre la culpabilidad de una persona puede ser extraída de procedimientos penales en los que no

\footnotetext{
35 Caso Dimitrov y Hamanov v. Bulgaria (2011), párrafo 59.

36 Caso Dimitrov y Hamanov v. Bulgaria, TEDH (2011), párrafo 61.

37 Así, López, en Horvitz y López (2002) p. 79.

38 Respecto de la consagración normativa de este principio, el artículo 6.2 de la CEDH señala lo siguiente: "Toda persona acusada de una infracción se presume inocente hasta que su culpabilidad haya sido legalmente declarada." A su turno, el artículo 8.2 de la CADH señala, en su primera parte, que "[t]oda persona inculpada de delito tiene derecho a que se presuma su inocencia mientras no se establezca legalmente su culpabilidad", indicando luego un listado de garantías mínimas a las que toda persona tiene derecho durante el proceso.

39 Caso NAVALNYY Y OfITSEROV V. Rusia (2016), párrafo 84.

40 Caso Navalnyy y Ofitserov V. Rusia (2016), párrafo 91

41 Caso Navalnyy Y Ofitseron V. Rusia (2016), párrafo 92.
} 
ha participado, las decisiones judiciales deben ser redactadas de tal forma que se evite cualquier potencial prejuzgamiento sobre la culpabilidad de un tercero, para no poner en riesgo un examen justo de los cargos en procedimientos separados ${ }^{42}$. Indica que la primera y más obvia garantía para obtener seguridad en casos en que coacusados son juzgados en procedimientos separados, consiste en la obligación del tribunal de abstenerse de realizar cualquier declaración que pueda tener un efecto perjudicial en los procedimientos pendientes. Agrega que, si la naturaleza de los cargos hace inevitable que se involucren terceros en un procedimiento, y estos hallazgos son relevantes para la determinación de responsabilidad legal de estos terceros que son juzgados por separado, ello debería ser considerado como un obstáculo serio para la separación de los $\operatorname{casos}^{43}$.

La Corte señala que ningún hallazgo de hechos en el procedimiento en contra de "X" debió haber sido admitido en el caso en contra de los solicitantes, sin un examen completo y apropiado en los juicios posteriores. Del mismo modo, indica que, como el procedimiento seguido en contra de "X" fue acelerado, estableciéndose los hechos como resultado del plea bargaining, estos fueron legalmente asumidos más que probados, por lo que no podían haberse traspuesto a otros procedimientos penales sin que su admisibilidad y credibilidad fuera examinada y validada, como cualquier otra evidencia ${ }^{44}$.

Asimismo, afirma que la sentencia en contra de "X" tenía fuerza de cosa juzgada, incluso al ser emitida en un procedimiento acelerado. Sin embargo, no se podía predeterminar, por esa sentencia, la culpabilidad de quienes no participaron en ese juzgamiento ${ }^{45}$.

El fallo también aborda el tema de la participación posterior que tuvo el imputado "X" en el juicio seguido en contra de los solicitantes, indicando que se vio comprometida su calidad de testigo en este caso, puesto que su condena se basó en la versión formulada en el proceso de negociación y no fue requerido que su relato fuera revisado o corroborado con otra evidencia. Al declarar posteriormente como testigo, " $\mathrm{X}$ " fue obligado a repetir sus declaraciones hechas como acusado con base en el acuerdo de culpabilidad ${ }^{46}$, las cuales, señala la sentencia, no podían ser consideradas como referidas a hechos efectivamente probados, dada la naturaleza del procedimiento acelerado en el que se establecieron.

Este criterio fue también adoptado por el TEDH en 2019, en el caso Razvozzhayev v. Rusia y Ucrania y Udalstov v. Rusia, en el que un coimputado declaró en juicio en calidad de testigo, luego de haber arribado a un acuerdo en virtud de un procedimiento acelerado. Sin perjuicio de lo señalado, la Corte de Estrasburgo ha determinado que no existe vulneración a la garantía de un juicio justo en aquellos casos en que coimputados declaren en calidad de testigos, luego de haber obtenido un acuerdo de plea bargaining, siempre que dichas declaraciones sean también contrastadas con la prueba rendida y resulten concordantes con esta, mediante una apropiada y completa revisión. Así lo señaló en el fallo del caso Kadagishvili v. Georgia, relativo a un fraude bancario en que un número de coimpu-

\footnotetext{
42 Caso Navalnyy y Ofitserov V. Rusia (2016), párrafo 99.

43 Caso Navalnyy Y Ofitserov V. Rusia (2016), párrafo 104.

44 Caso Navalnyy Y Ofitserov V. Rusia (2016), párrafo 105.

45 Caso Navalnyy Y Ofitserov V. Rusia (2016), párrafo 107.

46 Caso Navalnyy y Ofitseron v. Rusia (2016), párrafo 109.
} 
tados obtuvo un acuerdo de conformidad y declaró posteriormente en el juicio seguido en contra de los demandantes ante el $\mathrm{TEDH}^{47}$.

\section{JUSTICIA PENAL NEGOCIADA Y RENUNCIA DEL DERECHO AL RECURSO}

El derecho al doble grado en materia penal goza de consagración en distintos cuerpos normativos internacionales sobre derechos humanos ${ }^{48}$.

El ya analizado fallo del caso Natsvlishvili y Togondize v. Georgia contempla una arista relacionada con este punto, puesto que el primer solicitante alegó una infracción al derecho al doble grado de jurisdicción en materia penal, consagrado en el artículo 2 del Protocolo No 7 de la CEDH, señalando que sufrió una limitación del derecho a apelar de la sentencia, al haberse contemplado la renuncia a esta garantía como parte del acuerdo suscrito por los intervinientes ${ }^{49}$.

El TEDH indica que es normal que el alcance del derecho de apelación sea más limitado respecto de una sentencia acordada en el plea bargaining, ya que representa una reducción del derecho a que el caso se resuelva sobre la base de sus méritos. Asimismo, señala que los Estados gozan de un amplio margen de apreciación de la disposición en análisis, por lo que esta restricción no iría en contra del espíritu del Protocolo No 7 y, por consiguiente, la limitación al derecho de apelación no puede considerarse arbitraria ${ }^{50}$. Añade que la aceptación del acuerdo por parte del solicitante fue consciente y voluntaria y contaba con los resguardos suficientes para que el acuerdo fuera válido, por lo que no existió violación de lo dispuesto en el artículo 2 del Protocolo No $7^{51}$.

En un fallo anterior, el TEDH ya había abordado la posibilidad de renunciar al derecho del doble grado jurisdiccional en materia penal. Este es el caso Litwin v. Alemania, cuya sentencia fue dictada el año 2011, y en el cual se alegó una infracción a lo dispuesto en el artículo 6 de la CEDH. En este caso, el solicitante fue detenido por ser sospechoso de cometer robos, comenzando el juicio en su contra el 19 de octubre del año 2000. En el quinto día de la audiencia de juicio, después de haber sido escuchada la evidencia, se fijó fecha de continuación de audiencia para el 17 de noviembre de ese año. Llegada la fecha señalada, y antes del inicio de la audiencia misma, se llevaron a cabo negociaciones entre los intervinientes. Según la versión del demandante, el tribunal, después de indicar la pena potencial de catorce años de presidio que podía ser impuesta, ofreció una condena de nueve años y medio, a cambio de la renuncia de su derecho a apelar de la sentencia, además de la renuncia suya y de su cónyuge de reclamar los bienes confiscados, acordando además que

\footnotetext{
47 Caso KadagishVili V. GEORGIA (2020), párrafo 157.

48 En el caso europeo, este derecho se consagró en el Protocolo No 7 de la CEDH, el que, en su artículo segundo, indica: "Toda persona declarada culpable de una infracción penal por un tribunal tendrá derecho a que la declaración de culpabilidad o la condena sea examinada por una jurisdicción superior", añadiendo que "[e]l ejercicio de ese derecho, incluidos los motivos por los cuales pueda ser ejercitado, se regularán por ley”. Por su parte, la CADH consagra, en el artículo 8.2 letra h), el derecho de recurrir del fallo ante juez o tribunal superior, como garantía mínima del proceso.

49 Caso NatsvlishVili Y Togondize V. GEORGIA (2014), párrafos 73 y 82.

50 Caso NatsvlishVili y Togondize V. GeORgIa (2014), párrafo 93.

51 Caso NatsvlishVili y Togondize V. Georgia (2014), párrafo 94.
} 
el solicitante no pediría más pruebas. Según lo señalado por el gobierno alemán, el fiscal no intervino en las negociaciones, siendo el tribunal el que, después de una propuesta del abogado del solicitante, prometió una pena menor a diez años de prisión a cambio de la renuncia de este último a reclamar sus bienes confiscados ${ }^{52}$.

En los argumentos esbozados por el demandante para alegar una infracción al artículo 6 de la $\mathrm{CEDH}$, se señaló que el tribunal de primera instancia ejerció presiones indebidas, en orden a inducirlo a renunciar a su derecho de apelación. Se indicó que el acuerdo logrado era inválido, puesto que el solicitante solamente actuó ante la amenaza de una sentencia de catorce años de presidio, lo que se suma al hecho de que no había tenido oportunidad de consultar con su abogado antes de renunciar a apelar de la sentencia ${ }^{53}$. La postura del gobierno alemán fue que el señor Litwin actuó acorde a su decisión voluntaria y libre de renunciar a su derecho de apelación, encontrándose habilitado para decidir libremente sobre ejercer dicho derecho o no y sin existir indicaciones de que el tribunal hubiera ejercido presiones indebidas o que hubiera existido un engaño al solicitante para inducirlo a alguna clase de error ${ }^{54}$.

El TEDH indica que la renuncia al derecho de apelación se encuentra permitida si se dan las condiciones de que sea realizada de forma inequívoca y que cuente con garantías mínimas ${ }^{55}$. Señala que no existió indicación de que el solicitante haya sido impedido de consultar con su abogado antes de la declaración, encontrándose este presente cuando se declaró la renuncia al derecho de apelación, por lo que tal renuncia no genera inconvenientes bajo lo dispuesto en el artículo 6 del Convenio Europeo ${ }^{56}$. La Corte concluye que existieron los resguardos suficientes para asegurar que el solicitante no se encontraba indebidamente influenciado al momento de efectuar su renuncia ${ }^{57}$.

\section{APLICACIÓN DE LOS CRITERIOS DEL TEDH A LOS MECANISMOS CHILENOS DE JUSTICIA PENAL NEGOCIADA}

De la sistematización jurisprudencial ofrecida puede colegirse que, para el TEDH, son condiciones de legitimidad de la regulación y del funcionamiento de los sistemas de justicia penal negociada: a) que los acuerdos sean adoptados en forma genuinamente voluntaria por el imputado; b) que sean celebrados con pleno conocimiento de sus consecuencias legales y de los hechos del caso, y c) que su contenido y la forma en que sean alcanzados estén sujetos a revisión judicial. Además, aun cuando solo se ha hecho en un voto disidente del fallo del caso Natsvlishvili y Togondize v. Georgia, se ha llamado la atención acerca de la incidencia que pueden tener, en el primero de esos requisitos de legitimidad, las condiciones carcelarias del imputado sujeto a prisión preventiva que celebra el acuerdo y las tasas

52 Caso LITWIN V. AlEMANIA (2011), párrafos 5 a 8.

53 Caso LiTWIN V. ALEMANIA (2011), párrafos 33 y 34.

54 Caso LITWIN V. ALEMANIA (2011), párrafo 36.

55 Caso LITWIN V. ALEMANIA (2011), párrafo 37.

56 Caso LITWIN V. ALEMANIA (2011), párrafo 39.

57 Caso Litwin V. Alemania (2011), párrafos 48 y 49. 
de condena en el juicio oral. También en ese voto disidente se ha señalado la conveniencia de contar con registros de las negociaciones. Asimismo, el TEDH ha destacado los peligros de que los acuerdos se celebren solo con uno de los varios coimputados y ha señalado que no es reprochable que forme parte de su contenido la renuncia del imputado a su derecho al recurso. A continuación, examinamos el grado de cumplimiento de estas ideas en el sistema chileno de justicia penal negociada.

\section{Mecanismos de JUSTICIA PENAL NegOCiAdA EN EL PROCESO PENAL CHILENO}

En el régimen procesal penal chileno, puede ser considerado como manifestación de justicia criminal negociada el procedimiento abreviado ${ }^{58-59}$. Ello es así, porque para que este procedimiento tenga lugar, es necesario, entre otros requisitos, que el imputado acepte los hechos de la acusación y los antecedentes de la investigación, pudiendo modificarse la acusación y la pena requerida para permitir su sustanciación, sin que la eventual condena, la que se basará en tales aceptación y antecedentes ${ }^{60}$, pueda imponer una pena superior a (ni más desfavorable que) la pena solicitada por el fiscal en su acusación (arts. 406 inc. $2^{\circ}$ y 412 inc. $\left.1^{\circ} \mathrm{CPP}\right)$.

Asimismo, admite ser considerado como expresión de justicia penal negociada el procedimiento simplificado con admisión de responsabilidad ${ }^{61}$, porque para que este se verifique, entre otras exigencias, se necesita que el imputado admita responsabilidad en los hechos del requerimiento, permitiéndose que se modifique la pena requerida para el evento de que dicha admisión tenga lugar, sin que se pueda imponer en la sentencia -la que también se fundará en tal admisión y en los antecedentes-, una pena superior a la pedida por el fiscal en aquella actuación (art. 395 CPP).

Además, también podría ser estimada, como manifestación (débil) de justicia criminal negociada, la no reclamación del imputado contra la resolución que acoge el requerimiento de procedimiento monitorio y la proposición allí contenida de imposición de una multa $^{62}$, en especial cuando es acompañada del pago de su monto dentro de los quince días siguientes a la notificación de tal resolución, porque a pesar de que en este caso no existe una negociación entre el fiscal y el imputado, igualmente está presente, además de una evidente simplificación procedimental, la lógica negociadora, pues este obtiene un beneficio penológico consistente en una considerable rebaja (25\%) en la cuantía de la multa (art. 392 CPP); si bien el imputado no negocia con el fiscal para conseguir una ventaja, la ley se la ofrece directamente ${ }^{63}$.

\footnotetext{
58 Matus (2011) p. 59; Maturana y Montero (2017) pp. 1341-1343.

59 Aun cuando no siempre exista una verdadera negociación, porque, eventualmente, el imputado podría aceptar este procedimiento solo para evitar ser juzgado en un juicio oral. Véase HorviTz, en Horvitz y López (2004) p. 522.

60 Cosa distinta es que, en la práctica, el efectivo examen de esos antecedentes no sea demasiado prolijo o no siempre se realice. Así, Horvitz (2012) p. 114.

${ }^{61}$ Con matices, Salas (2019) pp. 231-240.

${ }^{62}$ Así, López, en Horvitz y López (2002) p. 95. En contra, véase Rodríguez y Pino (2015) p. 1004, n. 4.

63 Oliver (2019c) p. 533.
} 
Una aproximación global a la regulación chilena de los mecanismos de justicia criminal negociada permite concluir que, en su diseño, en general, los requisitos mínimos de legitimidad exigidos por el TEDH, formalmente se cumplen. En efecto, de su revisión se desprende que, para que el imputado pueda renunciar a su derecho a un juicio oral y someterse a alguno de estos mecanismos, es necesario, salvo excepciones, el cumplimiento de los siguientes requisitos, inorgánicamente previstos en la ley: voluntariedad de la decisión, asesoría técnica y control judicial. A examinar tales requisitos y otros aspectos destinamos las siguientes líneas.

\section{EN RELACIÓN CON LA VOLUNTARIEDAD}

La exigencia del carácter voluntario de la renuncia coincide con el requerimiento del TEDH de que los acuerdos sean adoptados en forma genuinamente voluntaria por el imputado, y aparece claramente consagrada en materia de procedimiento abreviado (art. 409 $\mathrm{CPP}$ ), por lo que podría entendérsela incluida en la admisión de responsabilidad en el procedimiento simplificado, a pesar de que la regulación de este último no la señala expresamente, atendido que también importa una renuncia al juicio oral y que el primer inciso del artículo 395 CPP parece presuponer tal exigencia. Por la misma razón y pese a que la ley no lo establece explícitamente, resulta exigible que la no reclamación contra la resolución que acoge el requerimiento y la proposición de multa en el procedimiento monitorio sea voluntaria; si así no fuera, podría eventualmente invocarse fuerza mayor o caso fortuito para pedir al tribunal un nuevo plazo dentro del cual oponerse y manifestar voluntad de someterse a un juicio oral, conforme a lo dispuesto en el artículo $17 \mathrm{CPP}^{64}$.

No parece que en la voluntariedad de la decisión del imputado de aceptar un acuerdo tengan especial incidencia las tasas de condena en juicio oral -lo que es una de las preocupaciones manifestadas en voto disidente del TEDH-, ya que estas se sitúan entre el 73 y el 74 por ciento del total de juicios orales, cifra razonable y distante de la tasa de $99 \%$ del sistema de Georgia, como se advierte en la siguiente tabla.

TABLA 1

Número y porcentaje de absoluciones y condenas en juicio oral, en el período 2017-201965

\begin{tabular}{|c|c|c|r|}
\hline Año & Condenas & Absoluciones & \multicolumn{1}{c|}{ Total } \\
\hline 2017 & $8.155(73,81 \%)$ & $2.894(26,19 \%)$ & 11.049 \\
\hline 2018 & $7.558(73,34 \%)$ & $2.747(26,66 \%)$ & 10.305 \\
\hline 2019 & $7.159(74,10 \%)$ & $2.502(25,90 \%)$ & 9.661 \\
\hline
\end{tabular}

En cambio, sí debe ponerse atención a las condiciones carcelarias de los imputados presos que celebran los acuerdos -otra preocupación manifestada en voto disidente del TEDH-, ya que ellas pueden operar como un irresistible aliciente para renunciar al juicio y

\footnotetext{
64 Véase Horvitz, en Horvitz y López (2004) p. 498.

65 Esta tabla es de elaboración propia. La información sobre cantidad y resultados de juicios orales ha sido extraída de los Boletines Anuales Estadísticos 2017, 2018 y 2019 del Ministerio Público.
} 
aceptar cualquier negociación que se les ofrezca. Si se tiene a la vista el informe "Principales problemas detectados en las visitas de cárceles realizadas el año 2017 por los fiscales judiciales", de la Fiscal Judicial de la Corte Suprema, de 16 de febrero de 2018, puede concluirse que tales condiciones, en general, son deplorables. Se indica allí que las visitas de fiscales judiciales a 53 recintos penitenciarios del país durante el año 2017, permitieron constatar que en la mayoría de los recintos existe sobreocupación, y en algunos, un alto nivel de hacinamiento; que esta situación se ve agravada por el hecho de que los internos permanecen encerrados por alrededor de quince horas diarias, en celdas abarrotadas, sin servicios higiénicos, luz ni ventilación; que en algunos recintos el acceso al agua es insuficiente y, en general, no existe agua caliente; que el acceso a prestaciones de salud es deficitario; que algunos recintos poseen una deficiente infraestructura, etc.

En estas circunstancias y considerando que las condiciones carcelarias son comunes a los internos en prisión preventiva y a los internos condenados, porque los establecimientos penitenciarios en que unos y otros se encuentran son los mismos, no puede extrañar que el Subcomité para la prevención de la tortura y otros tratos o penas crueles, inhumanos o degradantes, en un informe de 27 de junio de 2016, sobre la realidad de las cárceles de Chile, constate la existencia de condiciones de sobrepoblación y hacinamiento en varias cárceles del país y califique tales condiciones como inaceptables estímulos para renunciar al derecho a un juicio y autoincriminarse (párrafos 29 a 31$)^{66}$.

Por otra parte, para cautelar el carácter voluntario de la aceptación del acuerdo por el imputado, debe tenerse presente la aprensión que un sector de la doctrina ha manifestado acerca de la necesidad de que la diferencia entre la pena imponible tras el acuerdo y la pena aplicable en el juicio no sea demasiado grande; mientras más amplia es esa diferencia, menos voluntariedad se atribuye a la decisión de renunciar al juicio ${ }^{67}$. El punto es preocupante, en particular respecto del procedimiento abreviado ${ }^{68}$, ya que tras la Ley No 20.931, de julio de 2016, tratándose de la mayor parte de los delitos de apropiación por medios materiales, como beneficio punitivo para quien renuncie al juicio oral, se estableció una rebaja de un grado de pena (art. 407 inc. $4^{\circ} \mathrm{CPP}$ ), lo que en los casos de crímenes constituye una diferencia considerable con la pena eventualmente imponible en juicio, al traducirse en cinco años menos ${ }^{69}$. Además, en la extensión de esa diferencia, también podría incidir una eventual inclinación a incrementar artificialmente los cargos contra el imputado al inicio del proceso $^{70}$, así como cierta tendencia, detectada y criticada por un sector de la doctrina nacio$\mathrm{nal}^{71}$, a reducir artificialmente los cargos iniciales, ofreciendo al imputado una pena inferior

\footnotetext{
${ }^{66}$ Así, Oliver (2019b) p. 1074.

67 DamašKa (2004) p. 1028; Schünemann (2005) pp. 107-108; Del Río (2009) pp. 196-197; Ferré (2018) p. 10.

68 Lo sugiere LANGER (2021) p. 19, al reconocer una posible coerción derivada de las diferencias de penas en estos casos. Véase, sin embargo, LANGER (2006) pp. 231-243, señalando que no basta con que exista una gran diferencia entre la pena imponible tras la negociación y la pena aplicable en el juicio, para calificar como coactiva la oferta del fiscal.

69 Críticos sobre esto, Riego (2017) p. 1103; Oliver (2019a) p. 462.

70 Fenómeno que ha sido denominado overcharging. Véase LippKe (2011) pp. 31-34.

71 Entre otros, Del Río (2008) pp. 167-169; Rodríguez y Pino (2015) pp. 1012-1018. Véase, en cambio, RIEGO (2001) pp. 464-465, quien, si entendemos bien, efectúa una valoración positiva de esta tendencia aun antes de su establecimiento en el sistema.
} 
a la legalmente correspondiente, para hacer más atractiva la oferta ${ }^{72}$. Aunque esto último ha sido criticado por los tribunales superiores ${ }^{73}$, lo cierto es que se trata de una tendencia respecto de la cual los tribunales inferiores, en general, se han mostrado complacientes ${ }^{74}$.

\section{EN CUANTO A LA ASESORÍA TÉCNICA}

La necesidad de asesoría técnica previa a la decisión de renunciar al juicio oral ${ }^{75}$ puede estimarse coincidente con la exigencia del TEDH de que el imputado que acepta el acuerdo lo haga con conocimiento de sus consecuencias legales, pues es esperable que estas consecuencias le sean informadas por su defensor. Tal necesidad es reconocida expresamente en el procedimiento abreviado, al menos cuando este tiene lugar en la audiencia de preparación del juicio oral, ya que es un requisito de validez de esta audiencia la presencia del defensor (art. 269 CPP). Y si bien es cierto que la ley no señala nada sobre el punto cuando el procedimiento abreviado se realiza en la audiencia especial del artículo 407 CPP, la conclusión debería ser la misma, dado el evidente contenido auto incriminatorio de las actuaciones que en tal audiencia el imputado puede realizar, no siendo por ello posible su defensa personal conforme al artículo 102 inciso final CPP, cuya constitucionalidad es incluso discutible a la luz del artículo 19 No 3 inciso cuarto de la Constitución. Por la misma razón, cuando tiene lugar la audiencia de admisión de responsabilidad en el procedimiento simplificado (art. 395 CPP), debería arribarse a idéntica conclusión, a pesar de que la ley no indica nada sobre el particular.

Sin embargo, tratándose del procedimiento monitorio, es evidente que la ley ha decidido prescindir de la exigencia de asesoría técnica al imputado, antes de que este renuncie al juicio oral no reclamando contra la resolución que acoge el requerimiento y la proposición de multa, o pida un juicio oponiéndose a esta resolución. Por algo, a diferencia de lo que sucede con la acusación en el procedimiento ordinario, la que debe individualizar no solo al imputado, sino también a su defensor [art. 259 letra a) CPP] y debe ser notificada a todos los intervinientes (art. 260 CPP), el requerimiento en el procedimiento monitorio solo debe individualizar al imputado (arts. 391 y $392 \mathrm{CPP}$ ), quien es la única persona a quien se notifica. No obstante, las consecuencias del "acuerdo" deben constar en la resolución que acoge el requerimiento de procedimiento monitorio (art. 392 inc. $2^{\circ} \mathrm{CPP}$ ), por lo que puede afirmarse que la notificación al imputado, en principio y sin perjuicio de lo que indicamos más adelante, permite poner en su conocimiento los efectos de su renuncia al juicio.

La otra exigencia de conocimiento que formula el TEDH, relativa a los hechos del caso, aparece formalmente cumplida con la obligatoria notificación al imputado de la acusación (en el procedimiento ordinario) o del requerimiento (en los procedimientos simplificado y monitorio), y la preceptiva inclusión en su contenido de los hechos que se le atribuyen [arts. 259 letra b), 391 letra b) y 392 CPP].

\footnotetext{
72 Oliver (2019a) p. 466.

73 Véase Contra C.J.T.B. (2016).

74 Entre muchas otras sentencias, puede verse Contra Bravo (2017), Contra IBARRA (2017), Contra ESPINA (2013), Contra FERrada (2013), Contra Zapata (2012).

75 Esta necesidad es puesta de relieve, entre otros, por BINDER (2004) p. 276.
} 
Como se comprenderá, para que en el procedimiento monitorio el imputado tenga conocimiento de los hechos que se le atribuyen y de los efectos de su renuncia al juicio, dado que esta se produce por la ausencia de reclamo dentro de plazo, es imprescindible que su notificación sea efectiva, la que, por ser generalmente la primera, debería hacerse en forma personal, entregándosele copia del requerimiento y de la resolución judicial (arts. 40 CPC y $52 \mathrm{CPP})$.

Sin embargo, en la práctica, muchas veces se presentan problemas derivados de la aplicación del apercibimiento previsto en el artículo 26 CPP, disposición que obliga al juez, al Ministerio Público o al funcionario que practique la primera notificación, a conminar a los intervinientes, en su primera intervención en el procedimiento, a indicar un domicilio dentro de los límites urbanos de la ciudad en que funciona el tribunal respectivo y en el cual puedan practicárseles las notificaciones posteriores (inc. $1^{\circ}$ ). Según la norma, si no se indica el domicilio, o no se comunica su cambio, o el domicilio señalado es inexacto o inexistente, "las resoluciones que se dictaren se notificarán por el estado diario" (inc. $2^{\circ}$ ). Es común que la policía, al tomar conocimiento de un hecho delictivo, conmine al imputado a cumplir con esta indicación de domicilio, dejando constancia de ello en un acta. El problema se suscita cuando, posteriormente, se intenta notificar en el domicilio indicado por el imputado la resolución que acoge el requerimiento de procedimiento monitorio e impone la multa, pero tal resolución no llega a su conocimiento por razones ajenas a su voluntad, como, por ejemplo, un error inadvertido en la constancia del domicilio en el acta levantada por la policía, una poco diligente búsqueda del domicilio en que debe practicarse la notificación, etc. En estos casos, hacer efectivo el apercibimiento y notificar por el estado diario la resolución que impone la multa puede dejar en indefensión al imputado, lo que en la práctica no siempre es considerado suficiente para declarar la nulidad procesal ${ }^{76}$.

Otros problemas se pueden presentar con la notificación acorde al artículo 44 $\mathrm{CPC}^{77}$. Por un lado, nada asegura que esta forma de notificación sea efectiva, ya que es posible que las copias del requerimiento y de la resolución que impone la multa no lleguen a manos del imputado ${ }^{78}$. Por otro lado -aunque esto no incide en el conocimiento que el imputado pueda o no tener de la resolución que le condena a una multa-, se advierte en la práctica un frecuente apartamiento de la legalidad, pues es común que la resolución que acoge el requerimiento y aplica la multa ordene sin más su notificación personal o conforme al citado artículo 44, pese a que este precepto exige que, primero, se realicen las búsquedas que dispone y se acredite que la persona a ser notificada se encuentra en el lugar del juicio y cuál es su morada o lugar de trabajo, y después, ordene el tribunal esta forma de notificación ${ }^{79}$.

En algunas legislaciones extranjeras más preocupadas de asegurar que, en procedimientos de esta clase, la decisión del imputado de renunciar al juicio sea adoptada en for-

\footnotetext{
76 Acogiendo incidentes de nulidad procesal deducidos en casos como estos, véase CONTRA ÁNGEL (2019) y Contra SAN MARTín (2019). Rechazándolos, Contra Mardones (2019), Contra VALDÉs (2019) y Contra MoliNA Y ALVARADO (2019).

77 Indica que esta notificación puede hacerse conforme a los artículos 40 ó 44 CPC, SALAS (2019) p. 344.

78 Aluden a estos problemas DURÁn y otros (2016) p. 138.

79 Entre muchas otras sentencias, véase CONTRA CASTillo (2020) y Contra MARTINez (2020).
} 
ma consciente, voluntaria e informada, se le cita a una audiencia junto con su defensor y se exige que en ella tal renuncia se manifieste en forma expresa. Es el caso, por ejemplo, del procedimiento por aceptación de decreto o monitorio español ${ }^{80}$.

Es dudoso que, en nuestro procedimiento monitorio, el imputado a quien se notifique el acogimiento del requerimiento y la imposición de la multa, cuente realmente con el conocimiento exigido por el TEDH. Es altamente probable que, producto de la ausencia de asesoría técnica ${ }^{81}$, el imputado no reclame contra la resolución que acoge el requerimiento e impone la multa, ignorando que se trata de un delito y creyendo que es solo un ilícito menor, equivalente en gravedad a una simple infracción a la ley del tránsito ${ }^{82}$. En la práctica, en la abrumadora mayoría de los casos el imputado no reclama contra dicha resolución, lo que se pretende demostrar con la siguiente tabla.

TABLA 2

Número y porcentaje de condenas en procedimiento monitorio conocidas por la Defensoría Penal Pública, en los años 2017 y $2018^{83}$

\begin{tabular}{|c|c|c|}
\hline Año & Total procedimientos monitorios & $\begin{array}{c}\text { Ingresos por procedimiento monitorio a } \\
\text { Defensoría Penal Pública }\end{array}$ \\
\hline 2017 & $75.527(100 \%)$ & $6.770(8,96 \%)$ \\
\hline 2018 & $75.267(100 \%)$ & $6.395(8,49 \%)$ \\
\hline
\end{tabular}

Esta tabla indica que menos del nueve por ciento de las resoluciones que acogen requerimientos en procedimiento monitorio llegan a conocimiento de la Defensoría Penal Pública, para decidir si se reclama o no en su contra; más del noventa por ciento de tales resoluciones no son conocidas por este organismo. Si bien es posible que algunas de estas últimas resoluciones sean reclamadas por el imputado con la asesoría de un defensor particular, es altamente probable que ello ocurra en un porcentaje estadísticamente irrelevante o, al menos, no especialmente significativo, ya que es sabido que la Defensoría Penal Pública atiende la abrumadora mayoría de las causas penales que se tramitan en el país y que requieren la intervención de un defensor ${ }^{84}$.

\footnotetext{
80 Véase López y Campaner (2017) p. 167. Admiten que este aspecto del procedimiento monitorio español revela una mayor preocupación por los derechos del imputado, BlanCO y Montesinos (2016) p. 298.

81 Reconoce esta usual ausencia de asesoría técnica, SÁEZ (2007) p. 14.

82 Hay otras posibilidades para explicar el no reclamo, como, por ejemplo, el mero temor del imputado a ver empeorada su situación. Alude a esta posibilidad, en relación con el procedimiento alemán por orden o mandato penal (Strafbefehlsverfahren), Aмвоs (1997) p. 340.

83 Esta tabla es de elaboración propia. La información sobre procedimientos monitorios ha sido obtenida gracias a gestiones de la Fiscalía Regional del Ministerio Público de Valparaíso. La información sobre ingresos de causas en procedimiento monitorio a la Defensoría Penal Pública ha sido extraída de los Informes estadísticos 2017 y 2018 de dicho organismo.

${ }^{84}$ Véase el Discurso Balance de Gestión 2016 del Defensor Nacional, en el sitio web de la Defensoría Penal Pública, donde se indica que este organismo atiende anualmente más del noventa por ciento de las causas penales.
} 


\section{EN RELACIÓN CON EL CONTROL JUDICIAL}

El control judicial es una exigencia coincidente con el tercer requerimiento del TEDH para el juicio de legitimidad de la justicia penal negociada, cuestión que se encuentra expresamente prevista en la ley en las renuncias al juicio oral que tienen lugar en el procedimiento abreviado y en la admisión de responsabilidad en el procedimiento simplificado, ya que ambos se verifican ante el juez de garantía. Dicho control se orienta no solo a la voluntariedad de la renuncia, sino también al cumplimiento de sus restantes requisitos de procedencia ${ }^{85}$. En el procedimiento monitorio también existe un control judicial, pero este, inexplicablemente, solo apunta al requerimiento y a la proposición de multa, no a la posterior renuncia al juicio oral que se produce si el imputado no reclama sobre su procedencia o monto.

La baja entidad de la sanción imponible en el procedimiento monitorio ha sido invocada para justificar sus características excepcionales ${ }^{86}$. No obstante, es muy discutible que la consideración del monto de la sanción que se impone pueda servir para justificar la prescindencia del control judicial (y de la asesoría técnica) de la renuncia al juicio oral, que tiene lugar cuando no se reclama contra la resolución que acoge el requerimiento y aplica la multa, y para legitimar la eventual vulneración del principio nulla poena sine iudicio, al imponerse una pena sin oír previamente al imputado ${ }^{87}$. No se debe pasar por alto el hecho de que el no pago de la multa puede dar lugar a una privación de libertad (art. 49 CP). Además, recientemente, la ley ha ampliado el ámbito de aplicación de este procedimiento, para aplicarlo no solo a faltas para las cuales el fiscal pide únicamente una pena de multa, sino también a ciertos simples delitos (art. 318 inc. $3^{\circ} \mathrm{CP}$ ) (Ley No 21.240, de 20 de junio de 2020); esta ampliación del ámbito de aplicación del procedimiento monitorio importa un ensanchamiento del alcance de las críticas dirigidas en su contra.

\section{EN CUANTO AL DEBER DE REGISTRO}

Por otro lado, no se ha establecido en la regulación chilena un deber de registrar las negociaciones previas a la aprobación del procedimiento abreviado o a la admisión de responsabilidad en el procedimiento simplificado. Sería del todo conveniente que existiera un registro de tales negociaciones ${ }^{88}$, tal como lo ha planteado un voto disidente del TEDH, pues su examen podría servir al juez como complemento en la tarea de verificación de las exigencias de voluntariedad y conocimiento. Del mismo modo, su existencia disminuiría el riesgo de que se obtenga una declaración autoincriminatoria del imputado a cambio del ofrecimiento de algún acuerdo que, en realidad, no se está dispuesto a celebrar ${ }^{89}$.

\footnotetext{
${ }^{85}$ Lo destaca SÁez (2007) pp. 10-22.

86 Así, Delgado (2015) p. 10.

87 En Italia, critica un procedimiento semejante (“procedimiento por decreto") FerRAJOLI (2000) p. 746, precisamente, por infringir el referido principio.

88 Lo sugiere para cualquier sistema procesal penal, DA SiLva (2016) p. 222.

89 Por esta y otras razones, a fines de los años sesenta del siglo pasado, en los Estados Unidos de Norteamérica se puso término al denominado plea bargaining "under the table" y se comenzó a exigir que las negociaciones se registraran en un acta. Véase De Diego Díez (1999) pp. 46-48.
} 
Que dicho riesgo existe en el sistema procesal penal chileno es algo que se puso de manifiesto en una muy conocida causa penal por delitos tributarios tramitada hace pocos años, en la que un defensor invocó, como fundamento de su petición de reapertura de la investigación y de que se practicaran ciertas diligencias, el hecho de que el fiscal no habría cumplido un compromiso adquirido con la defensa de solicitar un procedimiento abreviado y de no pedir la prisión preventiva contra dos imputados que, en virtud de dicho compromiso, habían renunciado a su derecho a guardar silencio y efectuado declaraciones autoincriminatorias ${ }^{90}$. Con independencia de que haya o no existido en dicha causa un incumplimiento de un compromiso por parte del fiscal, lo relevante es que la alegación que realizó la defensa como fundamento de su solicitud de reapertura de la investigación, solicitud que fue acogida por el tribunal, sugiere que en el sistema chileno el señalado peligro es real. Por algo en algunos sistemas extranjeros se exige que las negociaciones previas a la aprobación judicial de un acuerdo se registren ${ }^{91}$.

\section{EN RELACIÓN CON LOS ACUERDOS CON UNO DE VARIOS COIMPUTADOS}

En otro orden de ideas, los peligros que derivan de la posibilidad de que un acuerdo sea celebrado solo con uno de los varios coimputados, a que alude el TEDH, están presentes en el sistema chileno de justicia penal negociada, especialmente en el procedimiento abreviado. En oposición al modelo consensual, conforme al cual todos los coimputados deben manifestar su conformidad para que el acuerdo prospere, modelo que siguen algunas legislaciones extranjeras ${ }^{92}$, en Chile se ha optado por el modelo particularista, el cual permite que tenga lugar el procedimiento abreviado con uno de varios coimputados (art. 406 inc. $\left.3^{\circ} \mathrm{CPP}\right)^{93}$. Ello origina en la práctica del sistema procesal penal chileno los mismos problemas que el TEDH señala ${ }^{94}$, ya que no es infrecuente entre nosotros que, existiendo dos (o más) coimputados por un mismo delito, uno de ellos sea condenado en procedimiento abreviado y posteriormente declare como testigo en contra del otro en juicio, pese a que es discutible que se trate de un verdadero testigo, por declarar sobre un hecho aparentemente propio $^{95}$. Según nuestra opinión, buena parte de estos problemas se soluciona-

90 CONTRA DÉLANO Y LAVIN (2017).

91 En Alemania, por ejemplo, en una conocida sentencia de 19 de marzo de 2013, el Tribunal Constitucional Federal (Bundesverfassungsgericht), sin declarar inconstitucional la regulación de la Absprache, estimó contraria a la Ley Fundamental de Bonn la aplicación práctica que se ha hecho de dicha figura y exigió, entre otras cosas, que los acuerdos se registren, dejando constancia de los aspectos centrales de las negociaciones. Véase LocKER (2015) p. 40. Un comentario sobre dicha sentencia puede verse en RoLÓN (2013) pp. 315-344.

92 Por ejemplo, el Código Procesal Penal, Argentina (art. 431 bis No 8) y el Código Procesal Penal, peruano (art. 469).

93 Véanse estos modelos en Rivera (2009) p. 48.

94 Tales problemas se presentan no solo en nuestro país. Criticando algunos casos de la jurisprudencia española, puede verse MuÑoz (2003) pp. 69-84. Desde un punto de vista más general, abordando el complejo tema de la valoración de los coimputados en juicio, véase Miranda (2012) pp. 319-330.

95 En España, afirma que en un caso como este se declara como imputado, Miranda (1997), pp. 206-208. Señalan que se trata de verdaderos testigos De Diego (1997) pp. 358-359; Díaz (2006) pp. 115-123.

En Italia, existe una figura intermedia que podría aplicarse en estos casos: la de la persona imputada en un procedimiento o en un delito conexos (art. 210 Codice di Procedura Penale). Se parece al testigo en que tiene el de- 
ría, sin necesidad de modificar la ley para asumir un modelo consensual, si se reparara en que la calidad de imputado se mantiene hasta la completa ejecución del fallo (art. $7^{\circ}$ inc. $\left.1^{\circ} \mathrm{CPP}\right)$. Mientras no termine la ejecución de la sentencia, el coimputado condenado en procedimiento abreviado conserva su calidad de tal, por lo que no puede ser obligado a declarar como testigo en juicio contra otro coimputado por el mismo hecho; ello iría contra su derecho a guardar silencio. El ofrecimiento de tal declaración testimonial debería ser excluido en la audiencia de preparación del juicio oral ${ }^{96}$. Sin embargo, la Corte Suprema no advierte problemas en la utilización, como testigos, de coimputados condenados por el mismo hecho sobre el que declaran, señalando que "la incorporación como testigos de otros convictos en los mismos hechos, que ya fueron condenados, no está prohibida por norma legal alguna, en otras palabras, nada impide que coimputados puedan comparecer al juicio en esa calidad"97.

Por otra parte, el sistema chileno presenta el problema, advertido por los partidarios del modelo consensual ${ }^{98}$, de que permite la producción de situaciones contradictorias y difícilmente comprensibles por la sociedad, como la circunstancia de que un coimputado que acepta someterse a un procedimiento abreviado sea condenado y que, en cambio, aquel que participó en el mismo hecho delictivo pueda ser absuelto en juicio oral ${ }^{99}$. O bien, puede suceder que un coimputado sea condenado en procedimiento abreviado y que aquel que intervino en el mismo hecho también sea condenado en juicio oral, pero por un delito mucho más grave, como consecuencia de la aplicación de una calificación jurídica más severa ${ }^{100}$, o por el mismo delito, pero a una pena mucho más grave, a raíz de la invocación en juicio de agravantes que no fueron alegadas en el procedimiento abreviado ${ }^{101}$. Como se comprenderá, en esto último puede tener incidencia la actitud complaciente de los juzgados de garantía, constatada más arriba, de no evitar una reducción artificial de cargos por parte del Ministerio Público destinada a incentivar la aceptación de un procedimiento abreviado.

Además, el modelo particularista genera riesgos de atentado contra la igualdad ante la ley, al permitir que el fiscal decida negociar con uno de los coimputados y no con el otro, a pesar de que ambos puedan encontrarse en la misma situación. Estos riesgos se incrementan

ber de comparecer al juicio al que es citado. Pero se parece al imputado en que tiene la facultad de no responder las preguntas que se le dirijan y en que es asistido por un defensor.

96 En este sentido, Hermosilla (2019) pp. 275-277.

97 Contra L.A.F.S., M.L.B.P. y F.D.A.S. (2010) considerando décimo quinto.

98 Véase Lascuraín y Gascón (2018) p. 9; Lozano (2012) p. 349.

99 Como ejemplo de una situación de este tipo, puede verse Contra MENA (2018) y ConTRA VELASQUez (2021). En la primera causa, el coimputado acusado por un robo por sorpresa fue condenado en procedimiento abreviado; en la segunda, el coimputado acusado por el mismo robo por sorpresa fue absuelto en juicio oral. La misma situación puede observarse en CONTRA ALARCÓN (2019) y CONTRA CORTÉS (2019), pero respecto de un robo con intimidación.

100 Por ejemplo, véase CONTRA BUZETA (2017), causa en la cual el coimputado fue condenado en juicio oral por fraude al Fisco, pese a que los demás coimputados, quienes intervinieron en los mismos hechos y en idéntica calidad, habían sido condenados en procedimiento abreviado por fraude de subvenciones (art. 470 No $8 \mathrm{CP}$ ).

101 Verbigracia, véase CONTRA E.A.G.F. (2009), donde el imputado alega en su recurso de nulidad que en la condena (por robo) se le aplicó la agravante entonces existente en el No 3 del artículo 456 bis del CP (ser dos o más los malhechores), pese a que al coimputado que participó en el mismo delito y que fue condenado en procedimiento abreviado no se le aplicó dicha agravante. 
en Chile, como consecuencia de la inexistencia de un deber legal del fiscal de explicar las razones para ofrecer un procedimiento abreviado solo a uno de los coimputados y no a los demás, y de someter a control del juez su decisión de no ofrecerlo en un caso concreto ${ }^{102}$.

\section{EN CUANTO A LA RENUNCIA AL RECURSO COMO PARTE DEL CONTENIDO DE LOS ACUERDOS}

Por último, aun cuando el TEDH acepta que forme parte del contenido del acuerdo la renuncia al recurso, renuncia permitida en general en el artículo 354 CPP, debe reconocerse que se trata de algo peligroso, porque la exigencia de que el imputado renuncie al recurso para que prospere el acuerdo podría servir para encubrir una vulneración de sus derechos o una ilegalidad ${ }^{103}$. Además, el riesgo de que se esté condenando a un inocente, riesgo que es mayor en los procedimientos negociados que en el juicio oral ${ }^{104}$, clamaría por una revisión de la sentencia por un tribunal superior ${ }^{105}$.

Por eso, es preocupante la generalización de lo que en la práctica procesal penal chilena se ha venido en llamar procedimiento abreviado "cerrado", en oposición al denominado procedimiento abreviado "abierto". Este último se caracteriza por el hecho de que el acuerdo al que llegan previamente el fiscal y el imputado, deja abierta la posibilidad de la defensa de realizar ciertas solicitudes o alegaciones en la audiencia de procedimiento abreviado, como, por ejemplo, la petición de una pena sustitutiva. El "cerrado", en cambio, supone un compromiso por parte de la defensa de no realizar en la audiencia ninguna petición y, muchas veces, de renunciar al recurso contra la sentencia que se dicte. En la práctica, son muchos más los procedimientos abreviados "cerrados" que los "abiertos" 106 , lo que, por las razones apuntadas, resulta sumamente peligroso. El riesgo de que la negociación penal envuelva alguna ilegalidad o arbitrariedad, o de que conduzca a la condena de un inocente, aconseja no renunciar al recurso, máxime si, como se ha señalado más arriba, el control judicial del procedimiento abreviado por parte de los jueces de garantía no ha sido demasiado riguroso.

\section{CONCLUSIONES}

Para que los acuerdos en el proceso penal no vulneren lo dispuesto en la CEDH, el TEDH exige que sean adoptados voluntariamente por el imputado, con conocimiento de

\footnotetext{
102 Sobre el tema, Oliver (2019a) pp. 467-468.

103 Lo reconoce, teniendo a la vista el sistema procesal penal portugués, De FigUEIREDo (2011) pp. 93-97.

104 Véase DuCE (2019).

105 No deja de ser elocuente que, en Alemania, cuando la Absprache no contaba con regulación legal expresa (antes de 2009), el Tribunal Federal Supremo (Bundesgerichtshof), aceptando la legitimidad de estos acuerdos, en una conocida sentencia de 28 de agosto de 1997, exigió, entre otras cosas, que no pudiera renunciarse a los recursos contra las sentencias negociadas. Y cuando la Ordenanza Procesal Penal alemana pasó a regular la institución, consagró explícitamente la prohibición de insertar en los acuerdos una cláusula de renuncia al derecho a recurrir. Sobre el tema puede verse DiAS (2015) pp. 209-213.

106 Un reconocimiento de la existencia de esta práctica, en entrevistas a defensores, puede verse en ZAGMUTT (2019) pp. 88-89.
} 
sus consecuencias y de los hechos del caso, y con revisión judicial de su contenido y de la forma en que se alcanzan.

La exigencia de voluntariedad es expresamente recogida en la regulación del procedimiento abreviado. Y a pesar de que no se la menciona explícitamente en la regulación del procedimiento simplificado con admisión de responsabilidad ni en la del procedimiento monitorio, puede entendérsela tácitamente incluida.

Las aprensiones de un voto disidente del TEDH en el fallo del caso Natsvlishvili y Togondize v. Georgia, acerca de la incidencia de las tasas de condena en el juicio oral en la voluntariedad de la decisión de renunciar al juicio, no parece que tengan asidero en Chile. Sin embargo, sí es de recibo en el país la preocupación por las condiciones carcelarias del imputado sujeto a prisión preventiva que celebra el acuerdo. Las deplorables condiciones de muchos establecimientos penitenciarios obligan a ser especialmente cuidadoso en el examen de la real voluntariedad de dicha decisión. Asimismo, aun cuando el TEDH no ha planteado el punto, es preocupante la considerable entidad de la rebaja punitiva, no solo en el procedimiento abreviado de ciertos delitos contra la propiedad, sino en general, mediante modificaciones artificiales de los cargos contra el imputado, para frenar las cuales, en general, los tribunales no han sido demasiado rigurosos.

La exigencia de conocimiento de las consecuencias del acuerdo es coincidente con la asesoría técnica exigida por la ley en los procedimientos abreviado y simplificado con admisión de responsabilidad. Y si bien es cierto que en el procedimiento monitorio tal asesoría no es exigida, las consecuencias de la no oposición al requerimiento del fiscal se detallan en la resolución que se debe notificar al imputado.

La exigencia de conocimiento de los hechos del caso coincide con la necesidad legal de mencionar en la acusación o en el requerimiento los hechos que se atribuyen al imputado y de notificarle tales presentaciones. Pero en el caso del procedimiento monitorio, es riesgoso hacer depender la renuncia al juicio solo del transcurso de un tiempo desde la notificación del requerimiento. La aplicación del apercibimiento previsto en el artículo 26 CPP y la notificación practicada conforme al artículo 44 CPC han dado lugar a varios problemas. Existen en derecho comparado mejores opciones.

La exigencia de revisión judicial del acuerdo por el que se renuncia al juicio es recogida en el procedimiento abreviado y en la admisión de responsabilidad en el procedimiento simplificado, pero no en el procedimiento monitorio. Hay aquí una clara discordancia con los criterios de legitimidad fijados por el TEDH, que es dudoso que pueda justificarse solo por la baja entidad de la sanción imponible en este procedimiento.

En otro orden de ideas, sería conveniente que se estableciera legalmente un deber de registrar las negociaciones previas a la aprobación del procedimiento abreviado o a la admisión de responsabilidad en el procedimiento simplificado, tal como se hace en algunos sistemas extranjeros.

Dada la adhesión del sistema chileno de justicia penal negociada al modelo particularista, los peligros que el TEDH ha advertido en el hecho de que los acuerdos en el proceso penal se celebren solo con uno de los varios coimputados, son reales y están presentes en la práctica. Sin embargo, es posible plantear una interpretación legal que conjure algunos de esos riesgos, aun cuando la Corte Suprema no advierte en aquellos peligros un problema. 
Por último, a pesar de que el TEDH no lo reprocha, la generalización de una práctica que tiende a exigir, como parte de los acuerdos, que el imputado renuncie al recurso, lo que tiene lugar en lo que se ha venido en llamar procedimiento abreviado "cerrado", es inconveniente, considerando el mayor riesgo de condena a inocentes que se observa en la justicia penal negociada en comparación con el juicio oral, y la posibilidad de que la exigencia de renunciar al recurso sirva para encubrir ilegalidades o vulneraciones de derechos.

\section{BIBLIOGRAFÍA CITADA}

Aмвos, Kai (1997): "Procedimientos abreviados en el proceso penal alemán y en los proyectos de reforma sudamericanos", Boletín de la Facultad de Derecho UNED, No 12: pp. 305-362.

Bachmaier, Lorena (2018): "Justicia negociada y coerción. Reflexiones a la luz de la jurisprudencia del Tribunal Europeo de Derechos Humanos", Revista General de Derecho Procesal, No 44: pp. 1-30.

Binder, Alberto M. (2004): Introducción al Derecho procesal penal (Buenos Aires, Ad-Hoc, segunda edición, Ad-Hoc).

Blanco, Ana Isabel; Montesinos, Ana (2016): "Proceso por aceptación de decreto: el nuevo monitorio penal", Revista Boliviana de Derecho, No 22: pp. 290-299.

Cheesman, Samantha Joy (2014): A Comparative Analysis of Plea Bargaining and the Subsequent Tensions with an Effective and Fair Legal Defence (Szeged, Universidad de Szeged).

Correa Robles, Carlos; Reyes López, Mauricio (2012): El procedimiento abreviado y la justicia criminal negociada. Derecho chileno y comparado (Santiago, Editorial Jurídica de Chile).

Da Silva Brandalise, Rodrigo (2016): Justiça Penal Negociada. Negociação de sentença criminal e princípios processuais relevantes (Curitiba, Juruá Editora).

DAMAŠKA, Mirjan (2004): "Negotiated Justice in International Criminal Courts", Journal of International Criminal Justice, No 2: pp. 1018-1039.

De Diego Díez, Luis Alfredo (1999): Justicia Criminal Consensuada (Algunos modelos del derecho comparado en los EE.UU., Italia y Portugal) (Valencia, Tirant lo Blanch).

De Diego Díez, Luis Alfredo (1997): La conformidad del acusado (Valencia, Tirant lo Blanch).

De Figueiredo Dias, Jorge (2011): Acordos sobre a sentença em processo penal. O "fim" do Estado de Direito ou um novo "principio"? (Porto, Conselho Distrital do Porto da Ordem dos Advogados).

Del Corral, Diego (2010): Juicio abreviado (Buenos Aires, Astrea).

Del Río Ferretti, Carlos (2009): Proceso penal, consenso de las partes y enjuiciamiento jurisdiccional (Santiago, Librotecnia).

Del Río Ferretti, Carlos (2008): "El principio del consenso de las partes en el proceso penal y enjuiciamiento jurisdiccional: aclaraciones conceptuales necesarias", Revista Chilena de Derecho, vol. 35, No 1: pp. 157-182.

Delgado Castro, Jordi (2015): "Problemas y tensiones entre el diseño y funcionamiento del procedimiento monitorio penal”, Política Criminal, vol. 10, No 19: pp. 1-24. 
Dias, Leandro (2015): "Los acuerdos en Derecho penal en Karlsruhe y Estrasburgo: análisis de las recientes sentencias del Tribunal Constitucional Federal Alemán y del Tribunal Europeo de Derechos Humanos", Revista Pensar en Derecho, Año 4, No 6: pp. 195-243.

Díaz Pita, María Paula (2006): Conformidad, reconocimiento de hechos y pluralidad de imputados en el procedimiento abreviado (Valencia, Tirant lo Blanch).

Duce Julio, Mauricio (2019): "Los procedimientos abreviados y simplificados y el riesgo de condenas erróneas en Chile: resultados de una investigación empírica”, Revista de Derecho de la Universidad Católica del Norte, vol. 26. Disponible en: https://scielo.conicyt.cl/pdf/ rducn/v26/0718-9753-rducn-26-12.pdf. Fecha de consulta: 26 de agosto de 2020.

Durán Nicomán, Carolina y otros (2016): "El procedimiento monitorio penal en Chile: las consecuencias negativas de una innovación legislativa", Revista del Instituto Colombiano de Derecho Procesal, No 43: pp. 119-152.

Ferrajoli, Luigi (2000): Derecho y razón. Teoría del garantismo penal (trad. Perfecto Andrés Ibáñez, Alfonso Ruiz Miguel, Juan Carlos Bayón Mohino, Juan Terradillos Basoco y Rocío Cantarero Bandrés, Madrid, Trotta, cuarta edición).

Ferré, Juan Carlos (2018): "El Plea Bargaining, o cómo pervertir la justicia penal a través de un sistema de conformidades low cost”, Revista Electrónica de Ciencia Penal y Criminología, No 20-06: pp. 1-30.

Fiscal Judicial de la Corte Suprema (2018): Principales problemas detectados en las visitas de cárceles realizadas el año 2017 por los fiscales judiciales (Santiago, Fiscalía Judicial).

Hermosilla Iriarte, Francisco (2019): Valoración de las declaraciones de acusados y coimputados (Santiago, Librotecnia).

Herrera Guerrero, Mercedes (2014): La negociación en el nuevo proceso penal. Un análisis comparado (Lima, Palestra Editores).

Horvitz Lennon, María Inés (2012): "Seguridad y garantías: Derecho penal y procesal penal de prevención de peligros”, Revista de Estudios de la Justicia, No 16: pp. 99-118.

Horvitz Lennon, María Inés y López Masle, Julián (2002): Derecho procesal penal chileno, Tomo I (Santiago, Editorial Jurídica de Chile).

Horvitz Lennon, María Inés y López Masle, Julián (2004): Derecho procesal penal chileno, Tomo II (Santiago, Editorial Jurídica de Chile).

Langbein, John H. (1978): "Torture and Plea Bargaining", The University of Chicago Law Review, vol. 46, No 1: pp. 3-22.

Langer, Máximo (2021): "Plea bargaining, conviction without trial and the global administratization of criminal convictions", Annual Review of Criminology, No 4: pp. 1-35.

LANGer, Máximo (2006): "Rethinking plea bargaining: the practice and reform of prosecutorial adjudication in American criminal procedure", American Journal of Criminal Law, vol. 33, No 3: pp. 223-299.

LANGER, Máximo (2001): "La dicotomía acusatorio-inquisitivo y la importación de mecanismos procesales de la tradición jurídica anglosajona. Algunas reflexiones a partir del procedimiento abreviado", en MAIER, Julio y Bovino, Alberto (comps.), El procedimiento abreviado (Buenos Aires, Editores del Puerto) pp. 97-133.

Lascuraín Sánchez, Juan Antonio y Gascón Inchausti, Fernando (2018): “Por qué se conforman los inocentes?", In Dret, No 3: pp. 1-28. 
LiPPKE, Richard L. (2011): The ethics of plea bargaining (New York, Oxford University Press). LOCKER, Tobias (2015): Absprachen im Strafverfahren. Ein Überblick und alternative Verfahrensweisen (Hamburgo, Diplomica).

López Simó, Francisco y Campaner Muñoz, Jaime (2017): El proceso por aceptación de decreto o monitorio penal (Madrid, Reus).

Lozano Eiroa, Marta (2012): "Conformidad y pluralidad de acusados", Revista de Derecho UNED, No 10: pp. 347-365.

Maturana Miquel, Cristián y Montero López, Raúl (2017): Derecho Procesal Penal, Tomo II (Santiago, Librotecnia, tercera edición).

Matus Acuña, Jean Pierre (2011): "La justicia penal consensuada en el nuevo Código de Derecho Procesal Penal”, en Matus Acuña, Jean Pierre, Derecho penal, criminología y politica criminal en el cambio de siglo (Santiago, Editorial Jurídica de Chile) pp. 53-80.

Miranda Estrampes, Manuel (2012): “¿Cuál es el valor probatorio de la declaración de un coimputado? ¿En qué debe consistir la exigencia de corroboración de sus manifestaciones?”, en Miranda Estrampes, Manuel, Cerda San Martín, Rodrigo y Hermosilla IrIarte, Francisco, Práctica de la prueba en el juicio oral. Su valoración y el estándar del "más allá de toda duda razonable" (Santiago, Librotecnia) pp. 319-330.

Miranda Estrampes, Manuel (1997): La mínima actividad probatoria en el proceso penal (Barcelona, Bosch).

Muñoz Conde, Francisco (2003): La búsqueda de la verdad en el proceso penal (Buenos Aires, Hammurabi, segunda edición).

Oliver Calderón, Guillermo (2019a): "Reflexiones sobre los mecanismos de justicia penal negociada en Chile", Revista Chilena de Derecho, vol. 46, No 2: pp. 451-475.

Oliver Calderón, Guillermo (2019b): "Acuerdos en el proceso penal: hacia la morigeración de su carácter coactivo", en García Cavero, Percy y Chinguel Rivera, Alejandro (coords.), Derecho penal y persona. Libro Homenaje al Prof. Dr. H. C. Mult. Jesús-María Silva Sánchez (Lima, Editorial Ideas) pp. 1059-1076.

Oliver Calderón, Guillermo (2019c): "Estándar probatorio en los mecanismos chilenos de justicia penal negociada”, en Santibáñez Torres, María Elena (dir.), Marcazzolo AwaD, Ximena (coord.), La prueba en los procedimientos. VII Jornadas Nacionales de Derecho Procesal (Santiago, Thomson Reuters . Pontificia Universidad Católica de Chile) pp. 529-549.

Riego Ramírez, Cristián (2017): “El procedimiento abreviado en la Ley 20.931”, Política Criminal, vol. 12, No 24: pp. 1085-1105.

Riego Ramírez, Cristián (2001): "El procedimiento abreviado en Chile”, en Maier, Julio y Bovino, Alberto (comps.), El procedimiento abreviado (Buenos Aires, Editores del Puerto) pp. 453-475.

Rivera León, Mauro Arturo (2009): "Algunas consideraciones sobre el procedimiento abreviado”, Revista Jurídica Online: pp. 31-51. Disponible en: https://www.revistajuridicaonline.com/2009/09/algunas-consideraciones-sobre-el-procedimiento-abreviado/. Fecha de consulta: 24 de agosto de 2020. 
Rodríguez Vega, Manuel y Pino Reyes, Octavio (2015): “El principio de obligatoriedad en el ejercicio de la acción penal en los procedimientos jurisdiccionales basados en la autoincriminación", Revista Chilena de Derecho, vol. 42, No 3: pp. 1003-1033.

Rolón, Darío Nicolás (2013): "Los acuerdos en el procedimiento penal según la Corte Constitucional alemana”, Revista Chilena de Derecho y Ciencias Penales, vol. II, No 3: pp. 315-344.

Sáez Martin, Jorge (2007): "Controles judiciales en los procedimientos convencionales", Revista Procesal Penal, No 55: pp. 9-25.

Salas Astrain, Jaime (2019): Problemas del proceso penal. Investigación, etapa intermedia y procedimientos especiales (Santiago, Librotecnia, tercera edición).

Schünemann, Bernd (2005): La reforma del proceso penal (trad. Mariana Sacher, Madrid, Dykinson).

SUbCOMITÉ PARA LA PREVENCIÓN DE LA TORTURA Y OTROS TRATOS O PENAS CRUELES, INHUMANOS O DEGRADANTES (2016): Visita a Chile: recomendaciones y observaciones dirigidas al Estado parte (4-13 de abril de 2016).

Transparency International Georgia (2010): Plea Bargaining in Georgia. Disponible en: https:/www.transparency.ge/sites/default/files/TI\%20Georgia\%20-\%20Plea\%20 Bargaining\%20in\%20Georgia\%20ENG.pdf. Fecha de consulta: 24 de agosto de 2020.

Zagmutt Venegas, Valentina (2019): Procedimiento abreviado y simplificado en la práctica de audiencias chilenas. ¿Alguna vinculación con la condena de inocentes? (Santiago, Ediciones Jurídicas de Santiago).

\section{NORMAS E INSTRUMENTOS CITADOS}

ChILe, Código de Procedimiento Civil (30/8/1992).

Chile, Código Penal (12/11/1874).

Chile, Código Procesal Penal (12/10/2000).

Chile, Ley No 20.931 (5/7/2016), Facilita la aplicación efectiva de las penas establecidas para los delitos de robo, hurto y receptación y mejora la persecución penal en dichos delitos.

Chile, Ley No 21.240 (20/6/2020), Modifica el Código Penal y la Ley No 20.393 para sancionar la inobservancia del aislamiento u otra medida preventiva dispuesta por la autoridad sanitaria, en caso de epidemia o pandemia.

Convención Americana sobre Derechos Humanos (22/11/1969).

Convención Europea de Derechos Humanos (4/11/1950).

Protocolo No 7 de la Convención Europea de Derechos Humanos (22/11/1984).

\section{JURISPRUDENCIA CITADA}

Contra Velásquez (2021): Tribunal de Juicio Oral en lo Penal de Viña del Mar, 15 de enero de 2021 (juicio oral), RUC 1800167584-9.

Contra Martínez (2020): Juzgado de Garantía de Viña del Mar, 23 de diciembre de 2020 (procedimiento monitorio), RUC 2000610786-K. 
Contra Castillo (2020): Juzgado de Garantía de Viña del Mar, 27 de julio de 2020 (procedimiento monitorio), RUC 2000550285-4.

Contra Cortés (2019): Tribunal de Juicio Oral en lo Penal de Copiapó, 30 de septiembre de 2019 (juicio oral), RUC 1900350243-3.

Contra Alarcón (2019): Juzgado de Garantía de Copiapó, 31 de julio de 2019 (procedimiento abreviado), RUC 1900350243-3.

Contra MARDones (2019): Juzgado de Garantía de Quilpué, 24 de enero de 2019 (procedimiento monitorio), RUC 1800918379-1.

Contra SAN MARTín (2019): Juzgado de Garantía de Quilpué, 24 de enero de 2019 (procedimiento monitorio), RUC 1801022286-5.

CONTRA ÁNGEL (2019): Juzgado de Garantía de Quilpué, 9 de enero de 2019 (procedimiento monitorio), RUC 1800984696-0.

Contra VALDÉs (2019): Juzgado de Garantía de Quilpué, 9 de enero de 2019 (procedimiento monitorio), RUC 1801000028-5.

Contra Molina y AlVARado (2019): Juzgado de Garantía de Quilpué, 9 de enero de 2019 (procedimiento monitorio), RUC 1801055060-9.

Contra MENA (2018): Juzgado de Garantía de Viña del Mar, 18 de agosto de 2018 (procedimiento abreviado), RUC 1800167584-9.

Contra Buzeta (2017): Tribunal de Juicio Oral en lo Penal de Quillota, 25 de noviembre de 2017 (juicio oral), RUC 1200597905-4.

Contra DÉlano y LAVÍN (2017): $8^{\circ}$ Juzgado de Garantía de Santiago, 4 de abril de 2017 (audiencia de reapertura de investigación en procedimiento ordinario), RUC 1400637392-6.

Contra Bravo (2017): $7^{\circ}$ Juzgado de Garantía de Santiago, 11 de enero de 2017 (procedimiento abreviado), RUC 1500860418-2.

CONTRA IBARRA (2017): $7^{\circ}$ Juzgado de Garantía de Santiago, 4 de enero de 2017 (procedimiento abreviado), RUC 1600695538-3.

Contra C.J.T.B. (2016): Corte de Apelaciones de Valparaíso, 24 de octubre de 2016 (recurso de nulidad).

Contra Espina (2013): Juzgado de Garantía de Melipilla, 23 de enero de 2013, RUC 1200043071-2.

Contra Ferrada (2013): Juzgado de Garantía de Linares, 23 de enero de 2013, RUC 1200229891-9.

Contra Zapata (2012): Juzgado de Garantía de Coquimbo, 19 de diciembre de 2012, RUC 1000055500-8.

Contra L.A.F.S., M.L.B.P. y F.D.A.S. (2010): Corte Suprema, 12 de julio de 2010 (recurso de nulidad), RUC 0500643407-1, Rol 3003-2010.

CONTRA E.A.G.F. (2009): Corte Suprema, 30 de marzo de 2009 (recurso de nulidad), RUC 0700928939-3, Rol 382-2009.

Tribunal Europeo de Derechos Humanos: KADAGISHVILI V. GEORGIA, TEDH, No 12391/06 (14 de mayo de 2020).

Tribunal Europeo de Derechos Humanos: RAZVOzZHAYEV V. RUSIA Y UCRANIA Y UDALTSOV V. RUSIA, TEDH, No 75734/12, 2695/15 y 55325/15 (19 de noviembre de 2019). 
Tribunal Europeo de Derechos Humanos: LEUSKA Y OTROS V. EstoniA, TEDH, No 64734/11 (7 de noviembre de 2017).

Tribunal Europeo de Derechos Humanos: NAVALNYY Y OFITSEROV V. Rusia, TEDH, No 46632/13 y 28671/14 (23 de febrero de 2016).

Tribunal Europeo de Derechos Humanos: Natsvisshvili y Togondize v. Georgia, TEDH, No 9043/05 (29 de abril de 2014).

Tribunal Europeo de Derechos Humanos: LITWIN V. AlEMANIA, TEDH, No 29090/06 (03 de noviembre de 2011).

Tribunal Europeo de Derechos Humanos: Dimitrov y Hamanov v. Bulgaria, TEDH, No $48059 / 06$ y 2708/09 (10 de mayo de 2011). 
